\title{
DEBATES
}

\section{Formas sociais, derivação e conformação}

\author{
Social forms, derivation and conformation
}

\author{
Alysson Leandro Mascaro
}

\section{Resumo}

Uma rigorosa compreensão da sociabilidade a partir das formas sociais contrasta tanto com velhas leituras marxistas, mais dadas a algum grau de historicismo, quanto com o institucionalismo liberal do pensamento universitário atual. Há determinação social pela mercadoria e pelo valor, a partir do trabalho abstrato: o fundamento da determinação é a produção. A equivalência entre mercadorias e entre seus possuidores erige formas por cujos constructos articulam-se as relaçóes sociais. Das formas nucleares da sociabilidade capitalista derivam uma forma política estatal e uma forma de subjetividade jurídica, específicas de tal modo de produção e inexoráveis a ele. A derivação de formas sociais se faz atravessada por contradiçóes e antagonismos factuais. Tais formas derivadas conformam-se em derivação secundária.

\section{Palavras-chave}

Formas Sociais; Determinação; Derivação de Formas; Conformação.

\begin{abstract}
A strict understanding of sociability by the social forms contrasts both with the old Marxist readings, more connected with some historicism level, as well with the liberal institutionalism of nowadays' academical thought. There is social determination by the commodity and by the value, which comes from the abstract labour: the foundation of such determination is the production. The equivalency between commodities and between their owners give rise to the forms by whose constructs social relations are articulated. From the nuclear forms of capitalist sociability derivates a political state form and a legal subjectivity form, which are specific and inexorable to this mode of production. The social forms derivation is crossed by contradictions and factual antagonisms. Such derived forms conform themselves in a secondary derivation.
\end{abstract}

\section{Keywords}

Social Forms; Determination; Derivation of Forms; Conformation. 


\section{6 | Alysson Leandro Mascaro}

\section{Introdução}

O pensamento marxista a respeito das formas sociais parte de uma busca de cientificidade material acerca das relações sociais no capitalismo. Nem sempre o marxismo assim se alicerçou: por largo tempo do século XX, leituras stalinistas de um lado e do chamado marxismo ocidental de outro acentuaram ou um mecanicismo de leis inexoráveis ou um devir social lido a partir de uma chave historicista, sem maiores cuidados com as formas constitutivas da sociabilidade, como se a dialética fosse, hegelianamente, um campo de contradições cujos conflitos revelariam por si só um movimento de sentido. E, além disso, já há algumas décadas, para além do marxismo, as ciências humanas operam numa recusa da determinação social, fazendo com que, se eventualmente lidem com categorias como a de forma social, o façam acreditando em condensações de sociabilidade ocasionais ou resultantes apenas de constrições de poder, de tal sorte que as formas sociais seriam um agrupamento no máximo coeso de práticas autogeradas e sem nexo intrínseco, carecendo, então, da materialidade última das abstrações reais erigidas a partir do modo de produção.

Ocorre que assentar as bases de uma leitura das formas sociais é estabelecer sua necessária correlação com a determinação social do capitalismo e suas especificidades históricas. Em razão de tal determinação é que se há de dizer que formas sociais derivam em outras. O fenômeno da derivação das formas sociais alcança a dinâmica de um processo ao mesmo tempo aberto e determinado, sem sujeito nem finalidade, mas feito por uma miríade de sujeitos e impulsionado pela valorização do valor. Num mesmo complexo, forma mercadoria, forma valor, forma dinheiro, forma Estado e forma jurídica constituem a nucleação inexorável e exemplar da derivação das formas sociais capitalistas.

A partir dos variados debates da derivação e dos desenvolvimentos empreendidos em "Estado e Forma Política", afirmarei dez pontos centrais a respeito do contexto teórico dos debates da derivação, das categorias de forma social e determinação social, da derivação das formas sociais e da sua conformação (MASCARO, 2013).

\section{Contexto teórico}

I) Os debates sobre determinação, formas sociais e derivação das formas são contemporâneos e contrastam com as insuficiências das teorias legitimadoras da sociabilidade capitalista.

As teorias materialistas sobre o Estado e a política despontam em momentos de crise estrutural do capitalismo. $\mathrm{Na}$ crise do fordismo e do Estado de bem-estar 
social, na década de 1970, abandonam-se as visões edulcoradas da neutralidade estatal, ou ao menos de sua instrumentalidade ou de um potencial uso transformador, criando-se as condiçôes para a compreensão da forma política estatal como derivada da forma mercadoria. O eventual refluxo parcial subsequente do debate da derivação se deveu à novidade ideológica do neoliberalismo como promotor de crescimento econômico, direitos humanos individuais, liberdade e igualdade de oportunidades. Tal falácia vai se desnudando com as crises em série do pós-fordismo, em especial aquela que desponta mundialmente em 2008. A partir de então, as análises que derivam a política do capital são incontornáveis para uma compreensão científica da reprodução social presente. Nem o Estado é distinto da economia de mercado ou empecilho ao seu desenvolvimento, como faz pensar o neoliberalismo, nem a crise se resolve com regulações estatais salvadoras, dado que a forma política estatal tem a mesma sorte da forma mercadoria e da forma valor, da qual é derivada. A crise do capitalismo só pode se resolver com a superação ou com o colapso de tal modo de produção (CALDAS, 2015; MASCARO, 2018).

II) A crítica marxista contemporânea à sociabilidade tem eixos teóricos centrais e diálogos tangenciais.

Proponho, em "Filosofia do Direito" (MASCARO, 2018), a existência de três caminhos do pensamento jurídico e político contemporâneo. As variadas teorias do Estado, na contemporaneidade, esparramam-se por essas três vertentes. Pelo eixo tradicional, dos juspositivismos, toma-se o Estado institucionalmente, mediante suas regulações normativas. Aqui se posicionam as leituras liberais atuais. Pelo caminho de leituras não-juspositivistas, uma vasta gama de leituras do poder transcende à institucionalidade normatizada para alcançar as práticas e as decisóes num plano já concreto. Mais além, pelo caminho das leituras críticas, marxistas, compreende-se a determinação histórica específica da reproduçáo social, tomando o poder a partir das formas sociais que surgem sob modo de produção capitalista, num trabalho a partir dos constructos específicos da sociabilidade. No que tange a tais leituras do marxismo contemporâneo, proponho o enfeixamento de suas vertentes em três eixos principais e um de tangente. Teorias que alcançam a analítica das formas sociais e sua dinâmica constituem o eixo central do debate marxista contemporâneo. $\mathrm{Na}$ economia, tal se dá com o debate sobre o valor - Rubin, Backhaus, Reichelt -; na política, com o debate sobre a derivação da forma política estatal - Hirsch, Altvater, Jessop, Elbe -; no direito, com o debate sobre a forma de subjetividade jurídica - Pachukanis, Cerroni, Edelman, Naves. Dois outros eixos laterais, de diálogo bastante próximo com a 


\section{8 | Alysson Leandro Mascaro}

leitura das formas sociais, de sua determinação e de sua derivação, são, de um lado, aqueles que fazem uma crítica à forma política estatal postulando, então, uma superação do capitalismo a partir de lutas por fora do Estado - Holloway, Negri - e, de outro lado, aqueles que insistem numa insuficiência das formas e contradiçóes sociais erigidas pelo capitalismo, como a própria luta de classes - dado que a classe trabalhadora também é um produto da sociabilidade capitalista -, erigindo então uma crítica do valor e de sua crise estrutural presente - Kurz, Jappe, Postone. Num eixo de tangente, variadas visões, ditas de pós-marxismo e de neomarxismo, muitas próximas de chaves psicanalíticas, também ensejam diálogo com uma teoria das formas sociais capitalistas - Deleuze, Badiou, Laclau, Mouffe, Žižek. Minha proposta é que tal grande campo, composto de um eixo central diretamente ligado ao tema, mais dois cujas preocupaçóes lhe podem ser enfeixadas, mais uma tangente de outros temas agregáveis, constitui o mais alto debate contemporâneo acerca da materialidade da sociabilidade presente, e, daí, representa o ponto de não-retorno da teoria política crítica contemporânea e o índice de suficiência científica para a ação social transformadora do presente (MASCARO, 2018).

\section{Forma social e determinação social}

IIII) O modo de produção capitalista é determinado socialmente e suas relações sociais tomam formas sociais específicas.

Formas sociais são constructos das relações sociais, operando tanto coerções quanto possibilidades da interação entre indivíduos, grupos e classes. Pode-se até dizer que haja, em cada modo de produção, formas específicas de sociabilidade, mas a sociedade capitalista é aquela que, de modo próprio, instaura uma abstração relacional impositiva, de tal sorte que, de maneira estrita, seria possível afirmar que apenas o capitalismo conhece formas sociais enquanto constrições independentes da vontade individual ou grupal ou de classes. $\mathrm{Na}$ medida em que erige uma determinação das possibilidades a partir da própria reprodução automática da mercadoria e do valor, e não apenas a partir do querer dos detentores dos meios de produção (embora não esteja alheio a tanto), o capitalismo não opera como o feudalismo ou o escravismo, para os quais o poder é dependente da vontade senhorial e tão peculiar quanto o capricho dessa vontade. No capitalismo, abandonam-se idiossincrasias ou laivos morais, humanistas, voluntaristas, impondo-se a força da mercadoria e da valorização do valor sobre todas as relaçôes sociais. Se se quiser tomar forma social de maneira ampla, podem-se no máximo verificar as formas sociais précapitalistas como determinantes contingenciais e erigidas a partir de sua factualidade, 
enquanto o capitalismo instaura uma determinação a partir de relaçóes sociais estruturadas conforme tal modo de produção. Engels (2019), em "A origem da família, da propriedade privada e do Estado", busca remontar as origens de tais formas à chegada da pré-história ao escravismo, confundindo as formas de apropriação no pré-capitalismo com a forma da propriedade privada no capitalismo. Leituras mais modernas, a exemplo de Gianfranco La Grassa na economia, buscam resgatar, no Marx (2019) de "O capital", a especificidade histórica das formas sociais capitalistas (HIRSCH, 2010; ALTHUSSER, 2015; LA GRASSA, 1975; MASCARO, 2019).

IV) A determinação pela forma social mercadoria advém da produção mediante trabalho abstrato.

Sociedades sob modo de produção capitalista são determinadas pela mercadoria, num processo voltado à acumulação e regido pela forma-valor. Não se funda na mera circulação mercantil o circuito da valorização do valor, e, sim, na produção, quando o trabalho sob condições capitalistas se torna trabalho abstrato, a partir da subsunção real do trabalho ao capital. Assim sendo, é no nível produtivo que se articula a determinação social: o capitalismo, separando os trabalhadores dos meios de produção, enseja a extração de mais-valor da força de trabalho assalariada pelos capitalistas, erigindo um circuito de acumulação que se reproduz. A produção e as trocas operam enredadas por uma dinâmica de valor. Não mais se apresentam, aqui, virtudes intrínsecas do produto quanto ao seu uso, nem tampouco qualidades do trabalho do trabalhador. Este é convertido em dispêndio de força de trabalho. Tal trabalho, que se torna indiferenciado, abstrato, permite uma equivalência entre as mercadorias que resultam de tal forma de produção. Nesse movimento, o valor da mercadoria resultará do tempo de trabalho socialmente necessário para sua produção. Como as mercadorias se intercambiam, passam a ter um valor de troca, erigindo então uma forma social de equivalência de valor nesse referenciação. Resulta desse movimento geral da abstraçáo do trabalho na produção de mercadorias e suas trocas uma forma geral do valor, que deságua na forma dinheiro. Se no feudalismo há uma concentração do trabalho e da produção em torno do feudo, numa sociabilidade capitalista passa a se dar uma divisão do trabalho a partir de unidades privadas independentes e, então, a circulação dos produtos se impóe sob forma mercantil. A forma dinheiro adquire um monopólio social de ser o intermédio geral das trocas mercantis, ganhando ainda uma condição específica monetária (MARX, 2011; 
ISAAK, 1980; HIRSCH, 2010; NAVES, 2014; MOLLO, 2013; GRESPAN, 2001; ERKERT, 2017; MASCARO, 2013).

V) A determinação pela forma mercantil deriva na equivalência relacional.

A determinação pela mercadoria impóe a equivalência geral como modelo de circulação e troca. Disso redunda uma sociabilidade da equivalência, que exatamente na igualdade e na liberdade opera a desigualdade e a constrição. A sociabilidade capitalista, em diferença da feudal ou da escravista, náo se erige a partir do domínio direto dos detentores sobre os não-detentores dos meios de produção. Não se trata nem do vínculo pela força bruta, como no caso do escravismo, nem do respeito à posse como tradição, como no caso feudal. A interação entre capitalistas e trabalhadores assalariados se dá por mecanismos voluntários, nos quais os agentes da produção tomam forma de sujeitos de direito. É pela autonomia da vontade de sujeitos tidos por iguais que se permite a exploração do trabalho e a extração do mais valor. Assim, a forma mercadoria e a forma valor se concretizam pelos sujeitos que as trocam. O trabalho abstrato enseja a generalizaçáo da mercadoria trabalho e do trabalhador. Dessa forma específica da produção se fundam as formas sociais correspondentes, como a de sujeito de direito. Na lembrança de Marx, as mercadorias não se trocam diretamente umas pelas outras no mercado. As trocas são realizadas por sujeitos de direito, que ao agir completam, em sua forma de sujeitos livres e iguais, a cadeia das formas sociais da mercadoria, da dinâmica do valor e da acumulação. As formas sociais constituem e constrangem os sujeitos que, ao se relacionarem na equivalência a partir da circulação mercantil, tecem essas mesmas formas (MARX, 2011; PACHUKANIS, 2017; NAVES, 2000; KASHIURA JR; 2014; MASCARO, 2013).

\section{Derivação das formas sociais}

VI) A forma política estatal deriva das relações de produção capitalistas.

A dinâmica do modo de produção capitalista se assenta na valorização do valor, mediante exploração do trabalho assalariado, circulação mercantil e apropriação dos meios de produção. Tais movimentos só podem existir erigindo uma forma política estatal terceira aos agentes da produção. No capitalismo, abre-se uma instância de poder político distinta daquela do poder econômico, constituindo o campo de possibilidades de ação do capital e, ainda, arbitrando a concorrência entre burgueses e entre estes e os trabalhadores. Tal figura política é específica do modo de produção capitalista, na medida em que feudalismo e escravismo são modos de produção nos quais os domínios econômico e político, no fundamental, se 
concentram nas mesmas mãos senhoriais. Em diferença do controle direto précapitalista, o capitalismo estabelece um controle social que é tanto direto quanto indireto: os capitalistas exercem imediatamente o poder econômico enquanto a existência do Estado dá ao capital as condiçôes mediatas para sua reprodução. Constituindo o espaço nacional e seu mercado, dotando-o de infraestrutura, estabelecendo as conexóes diplomáticas que permitem o intercâmbio capitalista internacional, normatizando, chancelando e reprimindo as relaçóes sociais, o Estado enseja a própria possibilidade de existência da dinâmica do capital. Da mercadoria ao Estado, trata-se de uma derivação de formas de relação social, não simplesmente de uma captura de pretensos poderes a-históricos pela burguesia. Uma forma política estatal vai se erigindo como forma terceira no intercâmbio entre burgueses e entre estes e os trabalhadores e os consumidores. Este papel político terceiro, via de regra, é até mesmo controlado, em suas figuras de comando, pela burguesia, mas não necessariamente assim o é, na medida em que não se trata de uma captura, mas sim de uma derivação de forma: havendo sociedades da exploração do trabalho assalariado com subsunção real do trabalho ao capital, numa miríade concorrencial, haverá um poder político terceiro a tais agentes. Se seu nome é Estado, se é democrático ou não, se é monárquico ou republicano, se é governado por burgueses ou por líderes trabalhadores ou militares, tudo isso é contingente. No estrutural, há uma forma política que tanto possibilita a valorização do valor quanto dela é derivada. O Estado é burguês não por captura ou domínio pela parte dos burgueses, mas sim por sua forma (HIRSCH, 2010; PACHUKANIS, 2017; CALDAS, 2015; HOLLOWAY e PICCIOTTO, 1979; ARTOUS et al., 2016; THAWAITES REY, 2007; ELBE, 2018; MASCARO, 2013).

VII) A derivação das formas sociais é factual, não lógica.

A derivação da forma mercadoria em forma política estatal não se faz por razóes de lógica interna do sistema social, nem por funcionalidade nem por padróes médios. Trata-se de uma derivação factual, plantada no solo das próprias relaçóes entre os agentes da produção no capitalismo. Não sendo uma força senhorial direta que garante propriedades e contratos, exsurge uma instância política distinta de burgueses e trabalhadores assalariados. Se no plano de compreensão lógica a existência da forma política estatal é contígua da própria forma mercadoria, na medida em que só há uma com a outra e não se pode dizer que haja uma hipótese de sustentação do econômico capitalista sem o político estatal - o que redundaria num economicismo isso não quer dizer, no entanto, que haja uma logicidade no processo histórico de 
concreção das formas. Sua existência não é lógica nos termos de sua razão de assentamento histórico nem tampouco plenamente funcional para os fins olímpicos de uma reprodução social plena ou idealmente imunizada de crises. Os Estados europeus surgem a partir de antigas submissóes senhoriais, cuja vassalagem se transforma em cortes, aproveitando velhas instituições para novas funções. Neste processo, não se dá uma total correspondência da forma política estatal com os interesses mercantis e da valorizaçáo do valor. Guerras, privilégios, idiossincrasias, lutas e antagonismos variados não permitem que a forma política estatal, derivada da forma mercadoria, seja totalmente funcional a esta - ainda que, em alguma parcela, haja de ser, sob risco de sucumbência política e econômica. A derivação, assim, é factual e sempre atravessada por contradiçôes e crises. No seio de cada sociedade e nas relaçóes internacionais, a forma política estatal é resultante e também constituinte de formaçóes sociais variadas: racistas, sexistas, patriarcais, homofóbicas, xenófobas, dependentes de ideologias, culturas, valores e religióes, enredadas por concorrências, estratégias e interesses múltiplos. Não há uma central intelectiva política do capitalismo que o torne funcional ou blindado a crises. A determinação social é relacional, não ideal nem lógica. A derivação das formas opera no solo da historicidade, onde também opera a luta de classes, grupos e indivíduos (HIRSCH, 2010; CALDAS, 2015; HOLLOWAY e PICCIOTTO, 1979; ALMEIDA, 2018; DEVULSKY, 2018; MASCARO, 2013).

VIII) A derivação da forma política erige Estados com autonomia material relativa.

A forma política estatal deriva da dinâmica da forma mercadoria, só existente em condições de trabalho abstrato, fazendo o tecido social ser determinado pela valorização do valor. Em tal dinâmica, os Estados são capitalistas não por uma captura política posterior, mas sim pela sua própria forma social, na medida em que permitem e garantem capitais e contratos. Para tanto, os Estados se armam com instituiçóes constituintes e repressoras. Ministérios, serviços de inteligência, setores de consecução de infraestrutura, escolas, poderes legislativos e judiciários, prisóes, polícias e exércitos são erigidos como instituições materiais de tal forma política terceira necessária à dinâmica do capital. Assim sendo, o Estado, como derivado da mercadoria, tem materialidade institucional e de aparelhos e, daí, autonomia relativa. Não se trata de uma autonomia suficiente para superar as estruturas do modo de produção capitalista, na medida em que o Estado é materialmente criado pelas - e dependente das - relaçóes da valorização do valor. No entanto, a autonomia, de modo parcial, permite ou não suficiência para câmbios médios internos - Estados 
neoliberais ou de bem-estar social, ditatoriais ou democráticos etc. A autonomia relativa do Estado pode se majorar pelas suas instituiçóes mas, inexoravelmente, sua natureza se submete como determinada pela forma-mercadoria. Por isso, mesmo governos de esquerda em Estados nacionais tendem a se direcionar pelo crescimento econômico do capital, na medida em que, com a acumulação, tributos sustentam a materialidade do Estado e a possibilidade de suas instituiçóes direcionarem açóes políticas progressistas. Sob modo de produção capitalista, os variados alcances da autonomia relativa do Estado só podem se fundar e só podem levar a distintos arranjos políticos, econômicos e sociais capitalistas, portando então, necessariamente, as contradições e as crises deste modo de produção. O socialismo não é possível a partir da forma política resultante do capitalismo, inexistindo proveitos miraculosos da autonomia política deste (HIRSCH, 2013; CALDAS, 2015 e 2018; MASCARO, 2013 e 2018).

IX) A forma mercadoria deriva em forma de subjetividade jurídica.

A determinação social pela mercadoria, na dinâmica da forma valor e da acumulação, erige tanto uma derivação de uma forma política terceira aos agentes da produção, estatal, quanto também molda esses próprios agentes da produção em suas relações sociais, dando às suas individualidades uma forma jurídica. A exploração do trabalhador no capitalismo se estrutura mediante a transformação do trabalho em mercadoria, de tal sorte que trabalhadores e capitalistas se vinculam de modo igual e livre por contratos, transacionando a força de trabalho. Também o acesso aos bens só poderá ser alcançado negocialmente, pela compra e venda. A circulação mercantil aí se funda, lastreada no trabalho. Para tanto, rompe-se com a antiga vinculação senhorial, pela força ou pela submissão em razão da tradição. Capitalistas e trabalhadores convertem-se em sujeitos de direito, numa equivalência para o vínculo que forja a desigualdade real, a exploraçáo, a extração de mais-valor e o lucro. Tal forma de subjetividade jurídica impóe-se às individualidades, que, a partir daí, ou vinculam seus atos obrigacionalmente - vontade recíproca - ou se póem sob crime. Num modo de produção de separação entre trabalhadores e meios de produção, a subjetividade jurídica é a maneira pela qual o sujeito de direito tanto se afirma como portador de liberdade e igualdade na circulação quanto, ao mesmo tempo, se submete ao sistema de propriedade privada de alguns e às ordens de repressão e normatização social. Assim, o sujeito de direito é, em especial, sujeito pelo direito. Tal forma social de subjetividade jurídica é derivada da própria forma mercantil, de tal modo que o sujeito de direito, cidadão, portador de direitos, é uma interpelação especificamente 
capitalista ao indivíduo. Seu assujeitamento e sua sujeição, nos termos de Althusser e da psicanálise, encontram no direito um elemento-chave de sua formalização social e sua determinação (PACHUKANIS, 2017; NAVES, 2000 e 2014; KASHIURA JR, 2009 e 2014; DAVOGLIO, 2018; MAGALHÃES, 2018; GILLOT, 2018; MASCARO, 2013).

\section{Conformação das formas sociais}

$\mathrm{X})$ Formas sociais se conformam em derivação secundária.

Formações sociais sob modo de produção capitalista são determinadas pela forma mercadoria e pela valorização do valor. De tal núcleo das relaçóes sociais derivam, inexoravelmente, a condição aos portadores de mercadoria de sujeitos de direito e, junto com isso, um poder político apartado dos agentes da produção, estatal. A relação entre Estado e direito é íntima, mas não porque uma das formas sociais crie a outra, e sim na medida da derivação de ambas da mesma matriz capitalista. A subjetividade jurídica não é uma criação estatal: a relação entre sujeitos na produção e na circulação cria uma condição material de equivalência, para os fins de vínculo mercantil, em face dos demais sujeitos. Historicamente, posteriormente à materialização de tais relações sociais capitalistas entre os indivíduos, os Estados tenderam a regulá-las, dando-lhes contornos normativos. Ocorre que não reside na normatividade estatal a criação da subjetividade jurídica. Esta é relacional, derivada diretamente da forma mercantil. Do mesmo modo, quando se toma o poder político terceiro, estatal, ele não aparece como poder bruto nas sociedades capitalistas, mas limitado pelos direitos subjetivos dos sujeitos de direito. Toda sorte de intervenção do Estado por sobre a propriedade privada acaba por ser, via de regra, objeto de indenizaçôes e reparaçôes mercantis aos sujeitos proprietários, ainda que em tempo diferido. Mesmo assim, não se pode dizer que o direito cria a forma política estatal ou lhe dá o campo de possibilidades. Historicamente também, Estados se dividem em poderes e competências juridicamente regulados, mas tal processo não cria a forma política pela jurídica. Dão-se, sim, ajustes de uma forma à outra. A tal dinâmica, denomino-a conformação entre formas sociais. $\mathrm{Na}$ sociabilidade capitalista, do núcleo da forma mercantil deriva, necessariamente, uma forma política estatal e uma forma jurídica. Estas, por sua vez, tendem a se conformar. A subjetividade jurídica, que é uma forma inexorável da relação social capitalista, passa a ser balizada por normas estatais: capacidades a partir de faixas etárias, vícios do negócio jurídico etc. Do mesmo modo, o Estado passa a ser balizado por regramentos jurídicos e, para muitos de seus fins administrativos e mesmo de direito internacional, é tomado como sujeito 
de direito em igualdade com quem contrata. A conformação é um processo de adaptação que dá contornos mais específicos às formas sociais. Em outra dinâmica, dá-se o mesmo com a forma dinheiro, que também é conformada pela forma política estatal e mesmo pela forma jurídica. Se o direito privado é eminentemente haurido da forma de subjetividade jurídica, muito do direito público se erige na conformação entre a própria forma jurídica e a forma política estatal. $\mathrm{O}$ direito processual é eminentemente um desses objetos resultantes de uma derivação secundária entre formas sociais já derivadas da forma mercadoria. No quadro da sociabilidade capitalista, a determinaçáo pela mercadoria gera formas sociais derivadas que, por sua vez, conformam-se em ajustes não necessariamente funcionais nem ideais, mas quase sempre coesos no que tange aos contornos finais de outras formas sociais daí secundariamente derivadas (MASCARO, 2013 e 2018; GRILLO, 2017).

Alysson Leandro Mascaro é Doutor e Livre-Docente em Filosofia e Teoria Geral do Direito pela Universidade de São Paulo (USP). Professor da Faculdade de Direito da USP (Largo São Francisco). Email: alysson@mascaro.adv.br.

\section{Referências}

ALMEIDA, Silvio Luiz de. O que é racismo estrutural? Belo Horizonte: Letramento, 2018.

ALTHUSSER, Louis. Por Marx. Campinas: Ed. Unicamp, 2015.

ARTOUS, Antonie; HAC, Tran Hai; SOLÍS GONZÁLEZ, José Luis; SALAMA, Pierre. Naturaleza y forma del Estado capitalista: análisis marxistas contemporâneos. Buenos Aires: Herramienta, 2016.

CALDAS, Camilo Onoda. A teoria da derivação do Estado e do direito. São Paulo: Outras Expressóes, 2015.

CALDAS, Camilo Onoda. Teoria geral do Estado. São Paulo: Ideias \& Letras, 2018.

DAVOGLIO, Pedro. Althusser e o direito. São Paulo: Ideias \& Letras, 2018.

DEVULSKY, Alessandra. Uma leitura marxista da questão identitária no direito. Margem Esquerda, v. 30, p. 35-42, 2018.

ELBE, Ingo. Pachukanis versus Lênin: dois paradigmas da crítica marxista do Estado. Margem Esquerda, v. 30, p. 25-34, 2018.

ENGELS, Friedrich. A origem da família, da propriedade privada e do Estado. São Paulo: Boitempo, 2019. 
16 | Alysson Leandro Mascaro

ERKERT, Jonathan Erik von. Valor-trabalho e forma jurídica. Tese (Doutorado em Filosofia e Teoria Geral do Direito). São Paulo, USP, 2017.

GILLOT, Pascale. Althusser e a psicanálise. São Paulo: Ideias \& Letras, 2018.

GRESPAN, Jorge. Marx crítico da teoria clássica do valor. Critica Marxista, v. 12, São Paulo, p. 5976, 2001.

GRILLO, Marcelo Gomes Franco. Direito processual e capitalismo. São Paulo, Outras expressóes, 2017.

HIRSCH, Joachim. Teoria materialista do Estado. Rio de Janeiro: Revan, 2010.

HOLLOWAY, John; PICCIOTTO, Sol (Orgs.). State and capital: a marxist debate. Austin:

University of Texas Press, 1979.

KASHIURA JR., Celso Naoto. Crítica da igualdade jurídica. São Paulo, Quartier Latin: 2009.

KASHIURA JR., Celso Naoto. Sujeito de direito e capitalismo. São Paulo, Outras expressóes, 2014.

LA GRASSA, Gianfranco. Valore e formazione sociale. Roma: Riuniti, 1975.

MAGALHÁES, Juliana Paula. Marxismo, humanismo e direito: Althusser e Garaudy. São Paulo: Ideias \& Letras, 2018.

MARX, Karl. O capital: crítica da economia política. Livro I. São Paulo, Boitempo, 2011.

MASCARO, Alysson Leandro. Estado e forma política. São Paulo: Boitempo, 2013.

MASCARO, Alysson Leandro. Filosofia do direito. São Paulo: Atlas, 2018.

MASCARO, Alysson Leandro. Introdução ao estudo do direito. São Paulo: Atlas, 2019.

MOLLO, Maria de Lourdes Rollemberg. A teoria marxista do valor-trabalho: divergências e convergências. Crítica Marxista, v. 37, p. 47-66, 2013.

NAVES, Márcio Bilharinho. A questão do direito em Marx. São Paulo: Outras expressóes, 2014.

NAVES, Márcio Bilharinho. Marxismo e direito: um estudo sobre Pachukanis. São Paulo: Boitempo, 2000.

PACHUKANIS, Evguiéni. Teoria geral do direito e marxismo. São Paulo: Boitempo, 2017.

RUBIN, Isaak. A teoria marxista do valor. São Paulo: Brasiliense, 1980.

THWAITES REY, Mabel. Estado y marxismo: un siglo y medio de debates. Buenos Aires, Prometeo, 2007.

Texto recebido em 07 de janeiro de 2019. Aprovado em 11 de março de 2019. 